\title{
A METHODOLOGY PROPOSAL FOR IDENTIFYING ENERGY LOSSES OF BUILDINGS WITH USE OF THERMAL IMAGING
}

\author{
BADIDA, M[iroslav] \& FRANKO, S[tefan]
}

\begin{abstract}
Thermal imaging of buildings and measurements of thermal bridges and bypasses is now widespread in terms of the Slovak Republic. Thermal imaging surveys of buildings' envelopes currently don't provide sufficient quality of information and results of these surveys are innacurate and of poor quality. It is a result of no common methodology present, that's why got into this field and created a new methodology for surveys of building's envelopes using thermal imaging camera. The new methodology provides step-by-step instructions for the best thermal imaging surveys possible.

Keywords:thermal imaging, methodology, buildings, building envelope, thermal bridges.
\end{abstract}

\section{INTRODUCTION AND CURRENT STATE}

There's was an analysis performed on the examples made by TIC measurements, which were in very many cases carried out only on the basis of general principles that most resulted in incorrect creation of IR thermal images and thus the misinterpretation of thermographic recordings.

Subsequently analysis and processing of thermal images was also weak, as in the case of facade insulation thermal images provided only information about individual points where the temperatures were indicated, in worse case temperature was not marked at all, anomalies and areas of insulation's faults were not described, in the worst case there was a visible reflected radiation present in the thermal images and these faults were even not documented in the report, nor eliminated.

Analysis of the current approach was made on the site of one of the TIC's measurements and thermal analysis of residential building's envelope done by a local company operating in a field of thermal imaging surveys. The result of the measurement is a report and evaluation of the current state of building's envelope to the date when thermal imaging tests were carried out.

The following was not described in detail, mainly weather conditions, in particular:

- wind speed and direction,

- ambient temperature fluctuation in the last 24 hours,

- the presence of rain in the last 24 hours,

- condition of the building's surface - wet, dry,

- relative air humidity.

Among other deficiencies belongs absence of these data:

- TIC distance from the measured object's surface,
- failure to measure the internal pressure of the building,

- internal temperature in the area of the anomaly,

- ambient temperature in the area of the anomaly,

- temperature background.

Summary of the analysis of the TIC measurement can lead to conclusion that thermal imaging measurements of the buildings are in the vast majority performed and evaluated only on the basis of personal preference, which are based on fundamental knowledge of the TIC area, they do not provide sufficient information knowledge of the area, not a single character, do not provide required information, the measurements are inaccurate in many cases, which is caused by the lack of uniform guidelines for this type of thermal imaging measurements.

Information on the procedures for the measurements and evaluation should be available not only for thermal imaging diagnostics, but also for the client of the thermal imaging measurements. It is very important to correctly interpret images from thermal imaging measurements to prevent errors in the implementation of corrective actions of a building.

An idea to design and create a new methodology for thermal imaging measurements and surveys of the buildings that could serve as a basis for identifying energy losses of buildings using thermal imaging cameras was therefore very timely and appropriate. This procedure or guidance could be further extended or modified for a particular type of building, type of measurement applied to the specific building etc. For determination of thermal bridging and heat release it is appropriate to design a brand new report of measurements, where the most common places of anomalies are described within the building's structure or in a particular place of anomaly's appearance or if further investigation is recommended.

\section{A NEW METHODOLOGY}

This methodology establishes a consistent approach to quantify the results of the review of the integrity of the thermal insulation of buildings. The purpose is to provide guidance that could serve as a rule or guideline for assessing the integrity of the insulation of buildings using thermal vision, whereby the Thermal Imaging Specialist to decide whether the building meets or does not meet the requirements imposed. It also includes requirements for the inspection of the building envelope using Thermal 
Imaging systems for locating poorly installed insulation, air leakage and thermal bypass.

This proposal presents guidelines for the use of thermal imaging cameras for external thermal survey of residential buildings and small industrial buildings.

The purpose of this methodological proposal is:

- Provide advice for those who want to become certified in Thermal Imaging measurements.

- Provide guidelines for the review and analysis of the use of TIC for detecting air penetration and inspection of thermal insulation.

This methodological proposal also includes information on:

- Thermal Imaging System used to determine differences in the radiation associated with changes in the surface temperature of the building envelope.

- Determination of whether the area to be imagined meets the specifications in this proposal.

- Documenting the type and extent of any observed thermal anomalies.

- Locating areas that require further physical examination combined with thermal bridges, thermal bypasses and air ingress.

- Providing thermal insulation characteristics indication and continuity.

- Identified areas affected by air and convection, Thermal Imaging System when used in combination with a "blower door" method.

This methodology proposal was created with the help of international standards as normative guidelines:

- ISO 6781: Thermal insulation - Qualitative detection of thermal irregularities in building envelope Infrared method.

- Canadian National Master Specifications (NMS), Paragraph 022713 Thermal Imaging evaluation; building envelope.

\section{CONDITIONS AND EQUIPMENT}

To achieve the best results from a survey of thermal insulation, it is important to take into account environmental conditions and use the most appropriate measurement of infrared technology for the task.

Infrared thermal anomalies are highlighted on the screen to the TIC specialist only where the temperature differences appear and environmental effects are taken into account. The following conditions should be fulfilled:

- The temperature difference in the structure of the building should be greater than $10{ }^{\circ} \mathrm{C}$.

- Temperature difference of the internal and external air should be greater than $5{ }^{\circ} \mathrm{C}$ in the last 12 hours prior to the survey / measurement.

- Temperature of the outside air should be within + / $3{ }^{\circ} \mathrm{C}$ for a duration of the survey / measurement, in addition to the previous hour.
- Temperature of the outside air should be within + / $10^{\circ} \mathrm{C}$ in the last 24 hours.

In addition, surveys should be in accordance with the following rules:

- Surfaces necessary for measuring without direct sunlight for at least 1 hour.

- No rainfall during the course of measurements, or just before it.

- Ensure that all surfaces investigated buildings are dry.

- Wind speed should be less than $12 \mathrm{~km} \cdot \mathrm{h}^{-1}$.

Thermal Imaging Survey to determine the continuity of thermal insulation, thermal bridging areas, heat transfer, must:

- Display of thermal anomalies.

- Identify the differences between the actual thermal anomalies, where temperature changes are caused by deficiencies in the thermal insulation and those that arise because of confounding factors such as changes in air movement, reflectivity and emissivity.

- Quantify the affected area in relation to the total thermally insulated area.

- Determine whether the anomalies and the thermal insulation of the building as a wholeis acceptable.

\section{Quantitative evaluation of thermal anomalies}

Any thermographic survey can show changes in apparent temperature areas within the field of TIC. For a use of surve, Thermal Imaging survey should systematically identify apparent defects and assess their relation to the criteria that have been previously agreed between the client and thermal imaging specialists. This research should reliably eliminate those anomalies that are not real defects and evaluate those real defects and communicate the results of measurements with the client. This methodology proposal provides access to:

1) The choice of the critical thermal parameter.

2) Selecting the maximum allowable defects.

3) Measuring changes in surface temperature caused by a defect.

4) Measurement of the defects

On the basis of the numerous steps proposed and all the new methodological procedures, a new algorithm (Fig. 2) for thermal imaging surveys was created and is a partial result of the research in this field. Verification of this methodology completes the whole process and it was done according to all proposed steps with superb results on a selected building. This verification resulted in areport that was also proposed as a part of the new methodology (Fig. 1). 


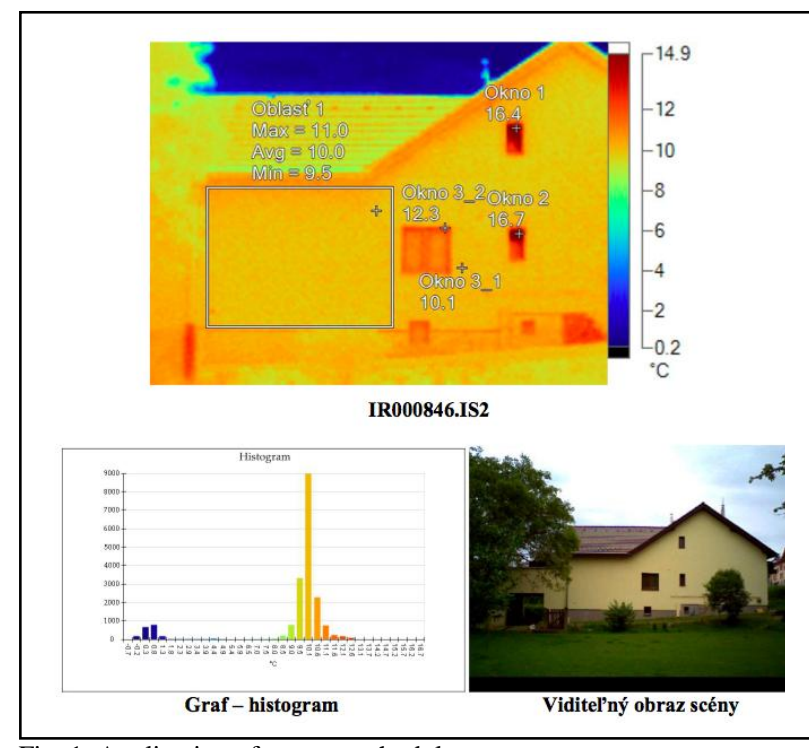

Fig. 1. Application of a new methodology

\section{METHODOLOGY OF PROCESSING REPORT FROM THERMAL IMAGING MEASUREMENT OF BUILDINGS}

Reports should be created for each specific type of Thermal Imaging measurements, whether it's a measure of insulation, air leakage and thermal bypass. Reports should include all of the following elements wherever possible and have been used in thermal imaging measurements:

1) A brief description of how the building was built.

2) Types of internal and external surface materials used in the building.

3) The geographical orientation of the building with a description of its surroundings, including other buildings, vegetation, landscaping and diversion of surface water

a. Manufacturer of a TIC, model and serial number.

b. Optional lenses with serial numbers (if available)

4) Date of last calibration.

5) Name Infrared inspection and other persons carrying out the measurement.

6) The date and time of surveys.

7) The internal temperature or air.

8) Outside temperature or air.

9) Temperatures of buffer zones and attic.

10) Indoor and outdoor relative humidity.

11)General data for the last 12 hours of sunlight appearance.

12) External conditions such as rainfall, direction and velocity of the wind in the last 24 hours, if the data can be detected.

13) Records of parts of buildings that did not meet the test conditions during Thermal Imaging and imaging records of the parts that were damaged adjacent buildings, interior cabinets, intervening cavities or reflective surfaces.

14) Other relevant information that could affect the test results.

15)Diagrams, sketches and / or photos describing the location of the building, where they were made thermal imaging pictures describing possible discrepancies in the components that have been tested.

16)Infrared images taken during the examination of the relative location of a written or voice recording explaining anomalies, together with the visual and reference images. Each point, line or area measurements recorded temperature display in thermal imaging cameras should also include information on the emissivity of a point, or the temperature setting and background.

17)Identification of aspects and components of the building, which is assessed.

18)It is necessary to include the results of an analysis that explains the nature and extent of any structural defects in the performance measurement of Thermal Imaging.

19) Any additional results of measurements and investigations. Identify other equipment used for the measurements, the type, model, serial number and any information on the last calibration.

\section{CONCLUSION}

Unlike the commonly used imaging methods of Thermal Imaging, a new methodology described by algorithm (Fig. 2) provides several benefits that are pillars for the correct identification of energy losses through building envelope using thermal vision:

a) can be precisely targeted to a particular problem and to work out the necessary requirements for a specific application of TIC,

b) provides precise conditions, requirements and methods in which to perform thermal imaging photography,

c) establishes the requirements for Infrared inspection for further consideration

d) determines the direction in which it could improve thermal imaging photography not only in this area,

e) defines the requirements for Thermal Imaging System and its features for a specific application,

f) provides guidance for the creation of high quality thermal imaging reports that are uniform and provide the detailed information of the measured object or entity,

g) makes a compact information provided by uniform transparent reports

h) increases the quality of output and customer satisfaction / Thermal Imaging measurements 


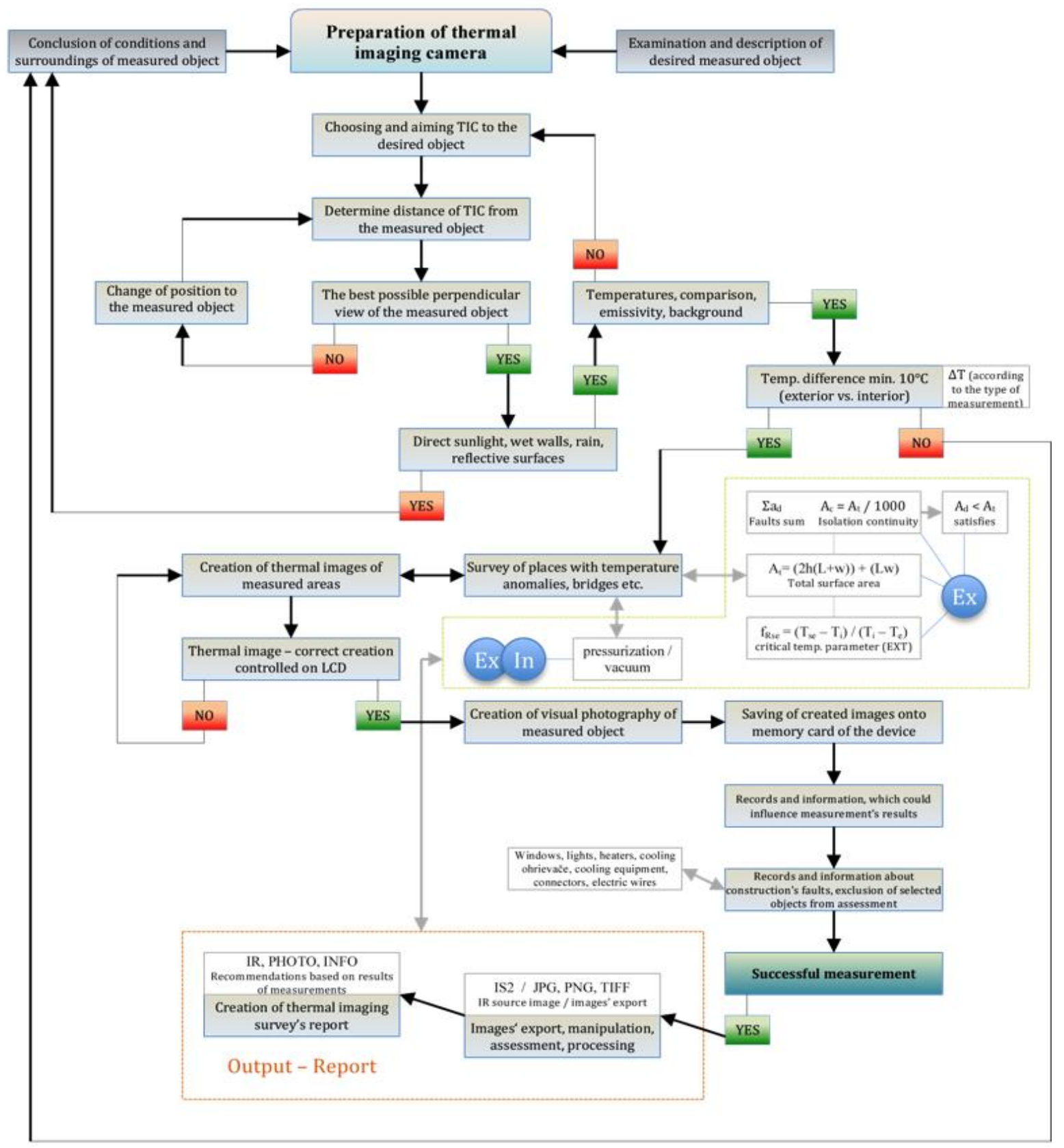

Fig. 2.Algorithm of a new methodology containing all the steps necessary for the best possible thermal imaging and assessment of building envelopes and their insulation

i) provides a reliable source of information for the implementation of corrective action errors caused by either poor construction practices, or improper use of materials, respectively. combination of both.

The methodology was applied to a specific case study can be regarded as sufficient and successful, as compared to conventional methodical procedure of Thermal Imaging, quality imaging was provided with a report on the building. Input data methodology served to create and implement a clear and accurate picture of thermal energy losses of the building. The information given in this way by the proposed method are much more accurate and easier to understand, compared to methodology used nowadays in Slovakia.

\section{REFERENCES}

[1] Franko, S.: Proposal of methodology for energy losses identification of buildings with use of thermal imaging. (Návrh metodiky identifikácie energetických únikov budov pomocou termovizie). Doctoral Thesis. Technical university of Kosice, Faculty of Mechanical Engineering. 189 p. Department of Environmental Studies, 2012

[2] Byrnes, J.: Unexploded Ordnance Detection and Mitigation. Springer, 2009. ISBN 978-1-40-209252-7

[3] NOWICKI, A.N.: Infrared Thermography Handbook, Volume 1: Principles and Practice. 2005, Norman Walker, ISBN 9780903132338. Volume 2: Applications. 2005, BINDT, ISBN 9780903132338

[4] Flir Systems AB: Thermal Imaging Guidebook for Building and Renewable energy applications. FLIR, ITC: 2011. T820325\{EN_uk $\}$ A 